\title{
The transition process of spina bifida patients to adult-centred care: An assessment of the Canadian urology landscape
}

\author{
Amy Wajchendler;, Peter Anderson, MD,2 Martin A. Koyle, MD, MSc ${ }^{3,4}$
}

'York University, Toronto, ON, Canada; ${ }^{2}$ Dalhousie University, Halifax, NS, Canada; ${ }^{3}$ Department of Surgery, University of Toronto, Section of Pediatric Urology, The Hospital for Sick Children and ${ }^{4}$ The Institute for Health Policy Management and Evaluation (IHPME), Toronto, ON, Canada

Cite as: Can Urol Assoc J 2017;11 (1-2Suppl1):S88-91. htrp://dx.doi.org/10.5489/cuai.4338

See related commentary on page $\mathbf{S 9 2 .}$

\section{Abstract}

Introduction: Due to medical advances over the past three decades, the vast majority of children with spina bifida (SB) now survive into adulthood. As a result, there is a need to implement a well-defined urological transition process for these patients from the pediatric to adult environment. The objective of this study was to identify and analyze the current medical practices employed and the attitudes regarding transition by Canadian pediatric urologists caring for the SB population. Methods: A survey consisting of 14 questions pertaining to physician demographics, current practice, and attitudes towards the transition process of SB patients was distributed at the 2015 annual Pediatric Urologists of Canada (PUC) conference. The survey respondents remained anonymous, and the data were collected and analyzed.

Results: A total of 28 surveys were collected from urologists across Canada (25 full-time pediatric, three also providing adult care), representing a $>75 \%$ response rate. The transition process was suggested to begin at the age of 18 or older by $43 \%(12 / 28)$ of pediatric urologists. The majority, $86 \%$ (24/28), do not currently use a questionnaire or a checklist to determine transition readiness of patients. Forty-six percent (13/28) of pediatric urologists do not provide ongoing urological care to their patients after referral has been made to adult-centred care. In the province of Ontario, in which $39 \%(11 / 28)$ of the pediatric urologists practice, $82 \%(9 / 11)$ are full-time pediatric urologists and $78 \%$ (7/9) do not provide ongoing care to SB patients after the age of 18 .

Conclusions: A significant minority of Canadian pediatric urologists perceive that the transition process should begin at the age of 18 or older. As such, it can be inferred that transfer of care and transition are synonymous, not independent. Simplistically, this suggests that transition represents an event rather than a longitudinal process. The fact there is no defined ongoing urological care as a component of this process, suggests the potential for substandard quality of care after these patients graduate to the adult sector. Different provincial healthcare systems and funding plans may further hinder this transition of care by denying provider continuity based on reimbursement plans.

\section{Introduction}

Spina bifida (SB) represents a clinical spectrum, ranging in degrees of severity. It is the most prevalent congenital birth defect affecting the spine. ${ }^{1}$ In addition to the disorder's potentially debilitating effects on the nervous system, there are many other organ systems affected, including the urological system. ${ }^{2}$ The life expectancy of those affected by SB in the not too distant past was very short, however, due to recent advances in medical care, this is no longer the case; 85-90\% of those born with SB live into adulthood. ${ }^{3}$ Historically, nearly a third of mortalities involving individuals diagnosed with SB/ myelomeningocele are as a result of urological complications. ${ }^{2}$ In North America, while in the pediatric age group, the majority of children with spinal defects are cared for in multispecialty clinics, supporting their medical and social needs. The lack of a well-defined transition process from pediatric to adult-centred care for individuals with SB has resulted in a reported two-thirds of adults with open $\mathrm{SB}$, who require long-term urological followup, neglecting to seek these services. ${ }^{4}$ For those who are seeking followup care in adulthood, many patients, particularly in the U.S., continue to see their pediatric urological specialists. ${ }^{5} \mathrm{~A}$ recent study conducted by Chan et al exemplifies the importance of routine urological followup into adulthood when studying a group of individuals with congenital urological disorders. ${ }^{6}$ After attending a transitional care clinic, $71 \%$ of adolescent/adult patients required a change in their bladder management and $38 \%$ underwent a major surgery. ${ }^{6}$

The objective of this study was to survey Canadian pediatric urologists in order to identify and analyze the current medical practices employed across Canada when transitioning patients with SB from pediatric to adult care, in addition to assessing their attitudes towards this process.

\section{Methods}

A survey form was created consisting of 14 , mainly binary (yes/no) questions pertaining to physician demographics, 
current practice, and attitudes towards the urological transition process of SB patients (Appendix A). The content for the questions was determined through conducting a comprehensive review of the pertinent literature. The survey was distributed at the 2015 annual Pediatric Urologists of Canada (PUC) and Canadian Urological Association (CUA) meetings held in Ottawa, ON. In addition, the survey was emailed to urologists who were unable to attend these conferences. The survey respondents remained anonymous, and the data was collected and analyzed. The results of the survey are expressed as percentages and absolute values.

\section{Results}

A total of 28 surveys were collected from the total of 37 PUC members across Canada (25 full-time pediatric, three also providing adult care), representing a $>75 \%$ response rate. There was a high completion rate and good representation was obtained from all major Canadian pediatric hospitals. In the province of Ontario, in which $39 \%(11 / 28)$ of the pediatric urologists practice, $82 \%(9 / 11)$ are full-time pediatric urologists. In addition, the contributing urologists had a relatively even distribution of start times in which they began practicing, with the average being the year 2000 (range 1984-2014). A summary of responses is shown in Table 1.

A transition process for SB patients was identified in $68 \%$ (19/28), with $82 \%$ (23/28) having a recipient adult urologist to care for adult SB patients as part of the process. Roughly half of the pediatric urologists (13/28) do not provide ongoing urological care to their patients after referral has been made to adult-centred care. Pediatric urologists in the province of Ontario comprise seven of the 13 respondents who do not provide ongoing urological care. Thirty-nine percent (11/28) of respondents suggested that the transition process should begin at the age of 18 or older. A questionnaire or checklist for readiness is not routinely used in $86 \%(24 / 28)$ of the centres.

Sexual function is formally discussed with male and female SB patients as part of transition by $82 \%$ (23/28) of respondents. In addition, it was reported that birth control and pregnancy are discussed with female SB patients by $71 \%(20 / 28)$ and $75 \%(21 / 28)$ of pediatric urologists, respectively. Forty-three percent (12/28) of respondents encourage patients to attend appointments independent of their parents as they grow older. Two of the participants commented that although they do not employ this practice, they agree that it is a good idea. Seventy-eight percent (22/28) of urologists surveyed believe that transition adult clinics should be the norm and should parallel the pediatric multidisciplinary clinics (as opposed to having a single-specialty provider).

Lastly, when asked what other diagnoses besides SB are where transition might be contemplated for ideal urological care, the top three responses were exstrophy (19/28), hypospadias (6/28), and posterior urethral valves $(6 / 28)$.

\begin{tabular}{|c|c|c|}
\hline Questionnaire item & $\begin{array}{l}\text { Yes } \\
(\%)\end{array}$ & $\begin{array}{l}\text { No } \\
(\%)\end{array}$ \\
\hline $\begin{array}{l}\text { 1. Do you have a transition process for SB patients } \\
\text { from adolescence to adulthood in place in your } \\
\text { centre? }\end{array}$ & 68 & 32 \\
\hline $\begin{array}{l}\text { 2. Do you personally provide the ongoing urological } \\
\text { care for SB patients after their transition from } \\
\text { pediatric care? }\end{array}$ & 54 & 46 \\
\hline $\begin{array}{l}\text { 3. Do you have an identified recipient adult or } \\
\text { transitional urologist in your community to care } \\
\text { for adult SB patients? }\end{array}$ & 82 & 18 \\
\hline $\begin{array}{l}\text { 4. Is sexual function formally discussed with your } \\
\text { male and female SB patients as part of transition? }\end{array}$ & 82 & 18 \\
\hline $\begin{array}{l}\text { 5. Do you feel transition adult clinics should be the } \\
\text { norm and parallel the pediatric multidisciplinary } \\
\text { clinics? }\end{array}$ & 75 & 25 \\
\hline $\begin{array}{l}\text { 6. Do you use a questionnaire or a checklist to } \\
\text { determine transition readiness of patients? }\end{array}$ & 14 & 86 \\
\hline $\begin{array}{l}\text { 7. If you are a pediatric urologist, do you encourage } \\
\text { patients to attend appointments independent of } \\
\text { their parents as they grow older? }\end{array}$ & 43 & 57 \\
\hline
\end{tabular}

\section{Discussion}

The survey that was created aimed to identify and analyze the current medical practices employed by Canadian pediatric urologists when transitioning patients with $\mathrm{SB}$, in addition to assessing their attitudes towards this process. We obtained a good representative sample for the study by securing participation from all major pediatric hospitals nationwide, which imparts confidence that the results obtained are a good reflection of the Canadian urological landscape.

One-third of pediatric urologists reported that they did not have a formal transition process for SB patients from adolescence to adulthood in place in their centre, yet $75 \%$ believed that a transition program is a critical aspect to a successful transition of medical care. Grant et al discuss the numerous transition models that are employed by different hospitals across Canada, such as the Good2Go model at The Hospital for Sick Children in Toronto and the ON TRAC model used at the Children's and Women's Health Centre in BC. ${ }^{7}$ Although foundationally these models share many similar features to satisfy the recommendations set forth by the Canadian Pediatric Society and the Society of Adolescent Health and Medicine, there still persists an overall lack of standardization across Canada with regards to the specific transition programs used for individuals who suffer from chronic illnesses. Seventy-five percent of participants felt that transition adult clinics should be the norm and should parallel the pediatric multidisciplinary clinics. This finding demonstrates good support for the implementation of these multidisciplinary adult clinics. SB is a condition that affects multiple organ systems and, therefore, adopting a multidis- 
Wajchendler et al.

ciplinary approach to the treatment of adults, as a continuation of the well-established pediatric clinics, would greatly benefit these individuals. ${ }^{1,5,8,9}$

Interestingly, 39\% of urologists suggested that the transition process should begin at the age of 18 or older. In most Canadian centres, this is when the transfer of care is expected to have already taken place from pediatric care. Mukherjee et al discuss the principles of transition, emphasizing that transition is not an abrupt event, that is, transition is not synonymous with transfer and, as such, is a process that should be initiated at a young age. Studies confirm that an early start to the transition process is preferred by individuals suffering from chronic illness. ${ }^{10}$ Currently, there is no definitive age to begin the transition process, however, it has been suggested to start as early as 12 years of age so that the patient will be ready to transfer around the age of $18 .^{11}$ The use of a questionnaire or checklist could be an effective tool to determine transition readiness of patients and may encourage an early implementation of a defined transition process. Eighty-six percent of the urologists surveyed do not currently use a questionnaire or checklist to determine transition readiness of patients. Sawicki et al argue that a questionnaire or checklist would enable pediatric healthcare providers to identify areas where a patient requires more education and training before their transfer to an adult healthcare provider. ${ }^{12}$ Furthermore, a self-administered assessment tool would ensure that an individual is prepared to successfully transition based on when they achieve independence, irrespective of age.

Whether it is an issue related to different provincial healthcare systems or the practice of the individual surgeons, $46 \%$ of the urologists surveyed do not provide ongoing urological care to their patients after referral has been made to adult-centred care. The fact that there is no defined ongoing urological care as a component of this process strengthens the conclusion that urologists view transition as an event rather than a process. The transition process should continue even after the transfer to an adult healthcare provider has occurred. Moreover, $18 \%$ of urologists reported they do not have an identified recipient adult or transitional urologist in their community to care for adult SB patients. Transition is intended to be a coordinated process that involves the transfer of care from a pediatric to an adult healthcare provider. Therefore, having adult healthcare providers who are eager to care for patients with SB is a critical aspect to a successful transition. ${ }^{8}$ Young et al found that a common barrier to transition in Canada for individuals who suffer from SB, cerebral palsy, and acquired brain injury was an inability to access adult physician specialists, which is an unforeseen finding due to Canada's government-funded healthcare system. ${ }^{13}$ It was determined that $7 / 9$ pediatric urologists from the province of Ontario do not provide ongoing care to SB patients after the age of 18 . Koyle et al have proposed that the alter- nate funding plan in Ontario potentially hampers provider continuity and suggested a culture change was necessary. ${ }^{14}$

Issues pertaining to sexual function and fertility are a challenging aspect of the transition process due to the fact that it is only in recent decades that the vast majority of SB patients are surviving into adulthood. In our study, it was reported that birth control and pregnancy are discussed with female SB patients by $71 \%$ and $75 \%$ of urologists, respectively. In addition, sexual function is formally discussed with male and female SB patients as part of transition by $82 \%$ of the urologists surveyed. Sexual and reproductive health are often inadequately discussed by pediatric healthcare providers, with pregnancy being a major issue with the transition process of SB patients. ${ }^{3}$ The results of the survey support this assertion, with a quarter of the respondents neglecting to discuss pregnancy with their patients. Furthermore, the results of Stephany et al's questionnaire that addressed factors of a successful transition of SB patients supported this fact by reporting that both patients and parents possess inadequate knowledge and have unanswered questions pertaining to these topics. ${ }^{15}$ Early and in-depth discussions of sexual and reproductive health are critical to a smooth transition to adult-centred care.

Forty-three percent of survey respondents encouraged patients to attend appointments independent of their parents as they grow older. Two of the participants commented that although they do not use this approach, they believe that it is a good idea. Toronto's Holland Bloorview's SB transition pamphlet encourages young teenagers to attend part of the medical appointment by themselves to develop self-advocacy skills. ${ }^{16}$ Lindsay et al explained that it is common in Ontario for parents to only attend a portion of their child's appointments when they are in a pediatric setting, thus enabling their child to discuss sensitive topics with their physicians, in addition to promoting patient autonomy. ${ }^{17}$ Moreover, in van der Toorn et al's study, it was also discussed how parental presence could prevent patients from discussing topics of sexuality with their urologist. ${ }^{10}$ With matters of sexuality already being a challenging component of the transition process, parental presence may create additional barriers. Furthermore, van der Toorn et al also determined in their study that nearly $25 \%$ of SB patients were irritated by their parent's overinvolvement. ${ }^{10}$ In order for patients to successfully transition to an adult healthcare provider, they must feel confident in their ability to manage their own healthcare needs. Encouraging patients to attend appointments independently of their parents helps to ease them into the adult healthcare system, in which attending appointments unaccompanied is the norm.

The primary limitation of the paper is that a survey was used to collect the data. Therefore, it was respondent-driven, and suffers from all of the problems that are inherent in survey research. However, despite the use of a survey, a 
$75 \%$ response rate was achieved and good representation was obtained from all major Canadian pediatric hospitals.

\section{Conclusion}

A significant minority of Canadian pediatric urologists $(39 \%)$ suggest that the transition process should begin at the age of 18 or older, an age when the transfer of care is expected to have already taken place from pediatric care in many jurisdictions. Therefore, it can be inferred that transition represents an event of transfer rather than a process. Furthermore, the fact that there is no defined ongoing urological care as a component of this process strengthens this conclusion. A standardized questionnaire or checklist could be an effective tool to determine transition readiness of patients and may encourage an early implementation of a defined transition process. Different healthcare systems and funding nationally may hinder the transition of care by denying provider continuity.

Competing interests: Dr. Koyle has been an advisor for Duchesnay. The remaining authors report no competing personal or financial interests.

This paper has been peer-reviewed.

\section{References}

1. Cox A, Breau L, Connor L, et al. Transition of care to an adult SB clinic: Patient perspectives and medical outcomes. J Urol 2011;186:1590-4. https://doi.org/10.1016/i.juro.2011.04.011

2. Snow-Lisy DC, Yerkes EB, Cheng EY. Update on urological management of SB from prenatal diagnosis to adulthood. J Urol 2015;194:288-96. https://doi.org/10.1016/i.juro.2015.03.107

3. Mukherjee $S$. Transition to adulthood in $S B$ : Changing roles and expectations. ScientificWorldJournalv2007;7:1890-5. https://doi.org/10.1100/tsw.2007.179

4. Wood HM, Wood D. Transition and lifelong care in congenital urology. 1st ed. Humana Press; c2015. 222 p. https://doi.org/10.1007/978-3-319-14042-1

5. Timberlake MD, Corbett ST, Costabile RA, et al. Identification of adolescent and adult patients receiving pediatric urological care and establishment of a dedicated transition clinic. J Pediatr Urol 2015;11:62. el-6. https://doi.org/10.1016/i.jpurol.2014.11.013

6. Chan R, Scovell J, Jeng Z, et al. The fate of transitional urology patients referred to a tertiary transitional care centre. Urology 2014;84:1544-8. https://doi.org/10.1016/i.urology.2014.08.022

7. Grant C, Pan J. A comparison of five transition programs for youth with chronic illness in Canada. Child Care Health Dev 2011;37:815-20. https://doi.org/10.1111/j.1365-2214.2011.01322.x

8. Binks JA, Barden WS, Burke TA, et al. What do we really know about the transition to adultcentred healthcare? A focus on cerebral palsy and SB. Arch Phys Med Rehabil 2007;88:1064-73. https://doi.org/10.1016/i.apmr.2007.04.018

9. Summers SJ, Elliott $S$, McAdams $S$, et al. Urological problems in SB patients transitioning to adult care. Urology 2014;84:440-4. https://doi.org/10.1016/j.urology.2014.03.041

10. van der Toorn $M$, Cobussen-Boekhorst $H$, Kwak K, et al. Needs of children with a chronic bladder in preparation for transfer to adult care. J Pediatr Urol 2013;9:509-15. https://doi.org/10.1016/i. jpurol.2012.05.007

11. Higuchi $T$, Holmdahl $G$, Kaefer $M$, et al. International consultation on urological diseases: Congenital anomalies of the genitalia in adolescence. Urology 2016;94:288-310. https://doi.org/10.1016/i. urology.2016.03.019

12. Sawicki GS, Lukens-Bull K, Yin X, et al. Measuring the transition readiness of youth with special healthcare needs: Validation of the TRAQ — Transition Readiness Assessment Questionnaire. J Pediatr Psychol 2011;36:160-71. https://doi.org/10.1093/ipepsy/isp128
13. Young NL, Barden WS, Mills WA, et al. Transition to adult-oriented healthcare: Perspectives of youth and adults with complex physical disabilities. Phys Occup Ther Pediatr 2009;29:345-61. https://doi.org/10.3109/01942630903245994

14. Koyle MA, Golda N, Hillis C, et al. A proposed solution to a urological tightrope walk: The challenge of transition of spina bifida patients from pediatric to adult care in Ontario. Can Urol Assoc J 2016;10:30610. http://dx.doi.org/10.5489/cuaj.4070

15. Stephany $H A$, Ching $C B$, Kaufman MR, et al. Transition of urological patients from pediatric to adult care: A preliminary assessment of readiness in SB patients. Urology 2015;85:959-63. https://doi.org/10.1016/j.urology.2014.12.019

16. Holland Bloorview's, 'A Timetable for Growing Up' pamphlet available online: http://hollandbloorview.ca/ programsandservices/programsservicesaz/spinabifidaandspinalcordservices. Accessed January 7, 2017.

17. Lindsay $\mathrm{S}$, Cruickshank $\mathrm{H}, \mathrm{Mc}$ Pherson $\mathrm{AC}$, et al. Implementation of an inter-agency transition model for youth with SB. Child Care Health Dev 2016;42:203-12. https://doi.org/10.1111/cch.12303

Correspondence: Dr. Martin A. Koyle, Department of Surgery, University of Toronto, Section of Pediatric Urology, The Hospital for Sick Children, Toronto, ON, Canada; martin.koyle@sickkids.ca

\section{Appendix A. Urological transitions of spina bifida (SB)} patients questionnaire

1) Are you a full-time pediatric urologist? Yes $\square$ No $\square$

2) Which province and city do you practice in? Province

3) What year did you begin practicing? Year

4) Do you have a transition process for SB patients from adolescence to adulthood in place in your centre? Yes $\square$ No $\square$

5) Do you personally provide the ongoing urological care for SB patients after their transition from pediatric care? Yes $\square$ No $\square$

6) Do you have an identified recipient adult or transitional urologist in your community to care for adult SB patients? Yes $\square$ No $\square$

7) Is sexual function formally discussed with your male and female SB patients as part of transition? Yes $\square$ No $\square$

8) Is pregnancy, as well as birth control, discussed with female SB patients as part of transition? Yes $\square$ No $\square$

9) Do you feel transition adult clinics should be the norm and parallel the pediatric multidisciplinary clinics (as opposed to having a single-specialty provider)?

10) Do you utilize a questionnaire or a checklist to determine transition readiness of patients?

Yes $\square$ No $\square$

11) At what age should the transition process begin, in general, for SB patients? Age

12) If you are a pediatric urologist, do you encourage patients to attend appointments independent of their parents as they grow older? Yes $\square \mathrm{No} \square$

13) If you answered 'yes' to question 12, at what age do you encourage patients to attend appointments independent of their parents?

Age

14) What are other diagnoses besides $S B$ where transition might be contemplated for ideal urological care? 